\title{
DISTRIBUIÇÃO DA BATUÍRA-DE-BANDO (Charadrius semipalmatus) AO LONGO DO ANO DE 1999 NA PRAIA DA ILHA COMPRIDA
}

\author{
BARBIERI, E.*; MENDONÇA, J.T.** \& S.C. XAVIER ${ }^{\star \star \star}$ \\ *Centro Universitário São Camilo. Av. Nazaré, 1501. Ipiranga. São Paulo (SP). **Insti- \\ tuto de Pesca SAA/SP, E-mail: cananeia@rgt.matrix.com.br, ${ }^{\star * \star}$ Centro de Estudos \\ Ecológicos Gaia Ambiental. Caixa postal 61, Cep. 11990-000. Cananéia. São Paulo.
}

RESUMO

\begin{abstract}
A Praia do município de llha Comprida (litoral sul de São Paulo) pode ser considerada como ponto de parada na rota migratória da batuíra-de-bando (Charadrius semipalmatus). Este trabaIho analisa a ocorrência sazonal da batuíra-de-bando e o impacto da distribuição humana para avaliar a importância da ilha como ponto de parada durante sua migração dessa ave. Para confirmar essa hipótese toda a praia foi percorrida semanalmente, registrando a ocorrência da espécie e contando o número de pessoas que se encontravam no trajeto. Os resultados obtidos mostraram que existe um pico no número de indivíduos no mês de janeiro e uma diminuição no inverno meridional (junho, julho, agosto), sendo que a abundância da batuíra-de-bando pode ser reduzida em até $80 \%$ em julho. Conclui-se, assim que a llha Comprida é uma importante área de parada para a alimentação e descanso do Charadrius semipalmatus, em sua migração tanto para sul quanto para o norte.
\end{abstract}

Palavras chaves: Migração, Charadrius semipalmatus, llha Comprida, Brasil.

\section{DISTRIBUITION OF THE SEMIPALMATED PLOVER (Charadrius semipalmatus) DURING 1999 ON THE ILHA COMPRIDA BEACH}

\begin{abstract}
The beach of Ilha Comprida is important site in the semipalmated plover (Charadrius semipalmatus) migration. This paper analyses the seasonal occurrence of the semipalmated plover at llha Comprida and the impact of human disturbance in order to avaluate the importance of the area as a stopover site. The sighted birds were counted and simultaneously they were registered the atmosphere where happened, activity type that they were accomplishing and the disturbance human if there was. The results show that Ilha Comprida areas seem to be an important stopover site during December, but not during winter (June, July and August), and the abundance of semipalmated plover may be reduced by $80 \%$ in July. The llha Comprida is stopover in the migration for the south and north and important area for foranging and rest, for the Charadrius semipalmatus.
\end{abstract}

Key Words: Migration, Charadrius semipalmatus, Ilha Comprida, Brazil

INTRODUÇÃO

Aves de praia neoárticas migram por várias rotas para a América do Sul, rumo às áreas não reprodutivas onde passam o inverno (Morrison, 1984, Myers et al., 1990). Uma dessas rotas importantes para as aves de praias incluem a Ilha Comprida situada no litoral sul

Apoio: Prefeitura Municipal de Ilha Comprida. 
do Estado de São Paulo (Barbieri et al., 1999, 2000) principalmente para a batuíra-de-bando (Charadrius semipalmatus) que são comumente vistas em grandes bandos durante a primavera e o verão na ilha.

A batuíra-de-bando pertence a família Charadriidae e a ordem Charadriiformes, reproduz no ártico e migra ao longo do continente americano até as áreas não reprodutivas do litoral brasileiro (Sick, 1997) trata-se de uma espécie migradora de grandes distâncias, especializada na interação de habitat-presa (Burger \& Gochfeld, 1991), que se concentram em grandes quantidades nas praias arenosas da llha Comprida.

Como outras aves de praia, a batuírade-bando depende dos habitats costeiros marinhos, durante sua migração (Myers et al., 1979). A rota seguida pôr esta espécie, ao abandonar os locais não reprodutivos na migração para o norte, entre março e abril pode ser traçada através da Amazônia e a costa sudeste dos Estados Unidos. Na migração para o sul, entre setembro e outubro a espécie abandona as áreas de cria para se dirigir aos locais não reprodutivos, passando pela costa oeste dos Estados Unidos, Caribe, norte do Brasil através da Amazônia, e Lagoa do Peixe (RS), chegando até a Terra do Fogo na Argentina (Belton, 1984).

Existem poucas informações com relação aos pontos de paradas para alimentação e descanso do Charadrius semipalmatus na costa do Brasil, bem como sua abundância e praias preferenciais. Devido à ocorrência desta espécie durante todo o ano, a praia da llha Comprida mostra-se de grande importância na migração do Charadrius semipalmatus, tanto quando se dirigem para os locais reprodutivos, quanto para os locais não reprodutivos. O presente trabalho quantifica a ocorrência ao longo do ano da batuíra-de-bando na Ilha Comprida, e evidência a importância da llha como ponto de parada durante a rota migratória, para alimentação e descanso do Charadrius semipalmatus.

\section{ÁREA DE ESTUDO}

No extremo sul do Estado de São Paulo ocorre o recuo da escarpa da Serra do Mar, formando a bacia hidrográfica do rio Ribeira de Iguape, cuja foz marca o limite norte do Complexo Estuarino-lagunar de Iguape - Cananéia - Paranaguá, estando a llha Comprida situada na região central. Esta ilha possui mais de 72 $\mathrm{km}$ de comprimento, com $3 \mathrm{~km}$ de largura em média, entrecortada por pequenos riachos, tornando-se um grande atrativo para aves e diversos outros animais (Figura 1).

A llha Comprida é uma ilha de barreira quaternária de sedimentação recente, predominantemente marinha (Suguio \& Martins, 1987). Formada pelo acúmulo de materiais arenosos (Tessler, 1988) e apresenta uma paisagem de destaque no litoral sul do Estado de São Paulo, sendo alvo de muitos trabalhos científicos em diversas áreas técnicas, porém de grande fragilidade à ocupação antrópica intensiva, visto que o ecossistema da região ainda mantém suas características naturais equilibradas. Sua vegetação, composta basicamente por restingas, mangues, brejos, dunas, praias e matas da planície atlântica, juntamente com sua fauna residente e com as aves visitantes do hemisfério norte e sul, formam um complexo ecossistema, onde ainda podem ser encontradas espécies de animais ameaçadas de extinção, como o papagaio-de-cara-rocha (Amazona brasiliensis) e o macuco (Tinamus solitarius).

As marés astronômicas têm uma altura de aproximadamente 1,50 metros, com uma marcante influência dos ventos no seu nível. A praia tem pouca declividade, resultando em uma zona de varrido com aproximadamente 20 metros de extensão. Nesta zona, os invertebrados ocorrem em altas densidades.

A situação da llha Comprida é mais favorável à urbanização, para fins turísticos do que os municípios de lguape e Cananéia, pois sua longa extensão de praia é um grande atrativo. Assim sendo, a llha Comprida apresenta 
ocupação, predominantemente turística, bastante desordenada, contendo ainda alguns poucos núcleos de comunidades tradicionais de pescadores.

A região apresenta valores pluviométricos máximos de janeiro a março com média mensal de 266,9 mm e mínimos em julho e agosto, de média mensal $95,3 \mathrm{~mm}$, sendo $2300 \mathrm{~mm}$ a precipitação média anual (Mishima et al., 1985, Silva, 1989)

\section{MATERIAL E MÉTODOS}

As contagens numéricas através do método itinerário fixo foram realizadas de janeiro a dezembro de 1999, com saídas semanais, somando um total de 48 amostras. Os censos iniciaram no período da manhã, com duração mínima de cada saída de 2:30 horas e máxima de 4:00 horas de observação (total: 200 horas; média de 2:30 horas/visita ( \pm 0:31 horas)). Escolheu-se o período da manhã pois durante a tarde há predominância de vento sudeste na região, este fato faz com que a maré suba muito, deixando inviável o trafego de veículos pela llha.

A praia da llha Comprida foi percorrida de carro, com velocidade média de $40 \mathrm{~km} / \mathrm{h}$, seguindo-se um transecto de $70 \mathrm{~km}$ por 200 metros preestabelecido, como utilizado por Vooren e Chiaradia, (1990), para a praia do Cassino no Rio Grande do Sul e proposto, por Bibby et al. (1992) para este tipo de ambiente também. O trajeto percorrido foi sempre inicia-

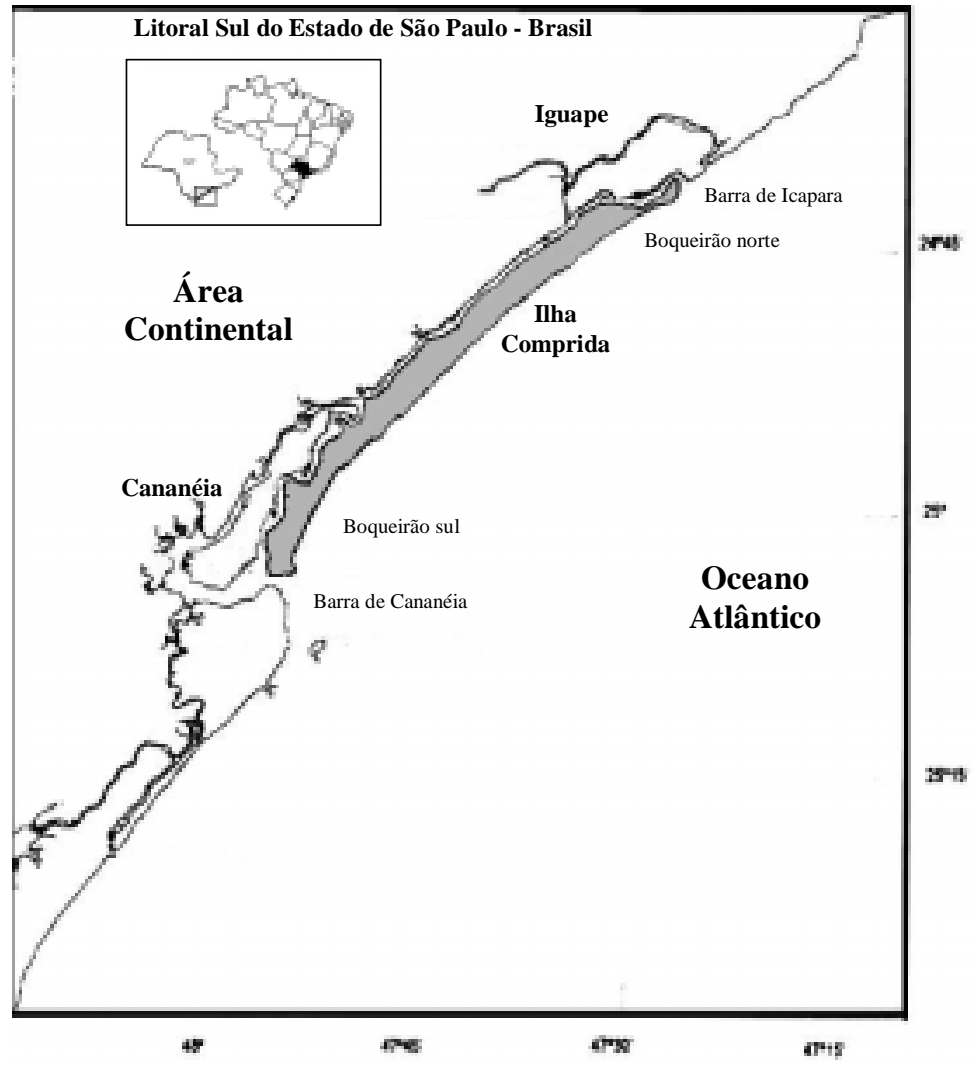

Figura 1 - Localização do município de llha Comprida, onde o trabalho foi realizado 
do na parte sul da ilha (Boqueirão Sul), trafegando em direção à parte norte (Canal de Icapara). As aves avistadas eram identificadas, contadas e fotografadas. Simultaneamente era registrado o ambiente onde ocorriam e tipo de atividade que estavam realizando (alimentação, descanso ou em vôo). Foram utilizados para auxiliar nas observações binóculos 7X50 e $20 \times 60$.

A freqüência de ocorrência das aves ao longo do ano foi calculada através da fórmula:

Freqüência de ocorrência $=$ (Número de visitas em que a espécie foi avistada/Número total de visitas) * 100

\section{RESULTADOS}

Os resultados indicam que trata-se de uma espécie comum na praia de llha Comprida, registrada regularmente ao longo do ano. $\mathrm{Na}$ Figura 2, observa-se que a maioria dos bandos de Charadrius semipalmatus começam a chegar na llha Comprida no final de agosto e princípio de setembro. No dia 15 de setembro observou-se um bando de 135 indivíduos na praia, sendo o maior bando registrado durante o trabalho. Durante a primavera austral e princípios do verão permanecem na zona uma média de 120 indivíduos, este número aumenta durante os meses de dezembro e janeiro e

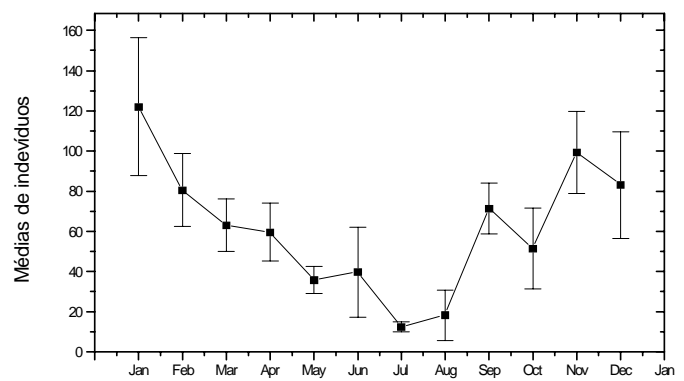

Figura 2 - Médias mensais de ocorrência de Charadrius semipalmatus ao longo do ano de 1999 na Ilha Comprida. Os valores correspondem as médias de 4 amostragem. As barras são os respectivos desvios padrões. diminui significativamente durante o inverno (Figura 3).

Nos meses de inverno observa-se uma diminuição do número de indivíduos que coincide com a época de passagem para o hemisfério norte (Figura 3). Durante a primeira semana de abril concentraram-se 113 indivíduos na praia, observou-se que a partir deste período o número de registros foram, paulatinamente diminuindo, fato que coincide com a época de voarem de volta para o hemisfério norte, para se reproduzirem.

As contagens indicam que o grosso da população abandona a Ilha Comprida no final de junho, apresentando para este mês uma baixa freqüência de ocorrência (Tabela 1). No dia 7 de maio observou-se 56 indivíduos e em julho de 1999, foram contados 25 indivíduos que permaneceram na área estudada durante o inverno austral, desaparecendo em meados de agosto. Estes indivíduos que ocorreram em juIho apresentavam plumagem de juvenis.

Analisando-se o número de $C$. semipalmatus em relação a presença humana, ao longo da praia, observa-se que houve uma tolerância desta ave ao fator antrópico, uma vez que o número da batuíra-de-bando não diminuiu com a presença humana, pois os bandos foram encontrados entre os grupos de banhistas durante o verão. Em algumas áreas da praia o número da batuíra-de-bando aumentou

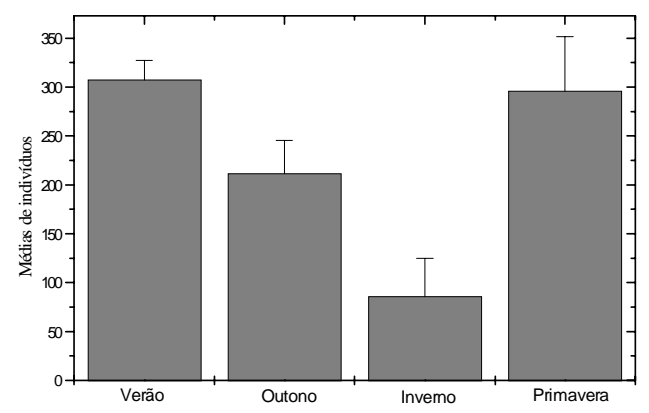

Figura 3 - Médias sazonal de ocorrência de Charadrius semipalmatus ao longo da praia da Ilha Comprida, durante o ano de 1999. Os valores correspondem à médias de 12 amostras. As barras são os respectivos desvios padrões. 
Tabela 1 - Número total de Charadrius semipalmatus avistados nos meses de 1999, com as respectivas médias, número de indivíduos por quilômetro e freqüência de ocorrência.

\begin{tabular}{lcccc}
\hline Meses & $\begin{array}{c}N^{\circ} \text { total de } C . \\
\text { semipalmatus }\end{array}$ & $\begin{array}{c}\text { Média mensal } \\
\text { Indivíduos/mês }\end{array}$ & Indivíduos/km & $\begin{array}{c}\text { Freqüência de } \\
\text { ocorrência em \% }\end{array}$ \\
\hline Janeiro & 268 & 123,2 & 1,88 & 100 \\
Fevereiro & 322 & 80,5 & 1,23 & 100 \\
Março & 252 & 63 & 0,96 & 80 \\
Abril & 238 & 59,5 & 0,91 & 70 \\
Maio & 143 & 35,7 & 0,54 & 60 \\
Junho & 159 & 39,7 & 0,61 & 30 \\
Julho & 25 & 6,25 & 0,12 & 20 \\
Agosto & 73 & 18,2 & 0,27 & 30 \\
Setembro & 285 & 71,25 & 0,87 & 50 \\
Outubro & 206 & 51,5 & 0,79 & 70 \\
Novembro & 397 & 99,2 & 1,52 & 100 \\
Dezembro & 332 & 83 & 1,27 & 100 \\
\hline \hline
\end{tabular}

proporcionalmente com o aumento do número de banhistas (Figura 4).

\section{DISCUSSÃO}

Estudos de outros autores citam a ocorrência da batuíra-de-bando para todo o litoral brasileiro (Vooren \& Chiaradia, 1990; Sick, 1997), porém não quantificam precisamente nem o número de indivíduos e nem as áreas preferenciais que costumam ocorrer ao longo do ano. Assim sendo, sabe-se ainda muito pouco sobre as áreas preferenciais de descanso e forrageio para esta espécie de ave, ao longo do litoral brasileiro.

Nossos resultados sugerem que o município de llha Comprida é uma das áreas de parada para o forrageio e descanso do Charadrius semipalmatus durante a migração de retorno para o hemisfério norte (abril) e para as áreas de forrageio do hemisfério sul (setembro). Observações feitas por Belton (1984) no Rio Grande do Sul (Brasil), registram grandes bandos da batuíra-de-bando voando para o hemisfério norte, passando pelo sul do Brasil no mês de abril.

Constatou-se que poucos indivíduos invernam na praia da llha Comprida, e a maioria da população migra mais ao sul para os sítios não reprodutivos da Praia do Cassino,
Lagoa do Peixe (Belton, 1984) e Terra do Fogo (De La Peña, 1986 ) durante o verão. De acordo com Sick (1997) estas aves migram para o hemisfério norte para se reproduzirem durante o inverno, assim os bandos observados neste período podem ser justificados pela presença de indivíduos imaturos que não acompanham a sua rota, como o já sugerido por Vooren \& Chiaradia (1990) para outras aves migratórias. Belton (1984) também relata um fenômeno similar no sul do Brasil, onde um grupo de Calidris canutus permanece na região do Rio Grande do Sul durante o verão boreal (julho).

As áreas de parada durante as rotas migratórias são importantes elos de ligação entre os locais não reprodutivos e os de procriação para as aves de praia (Famer \& Parent, 1997). O alimento obtido nas áreas de parada fornece energia para continuar o vôo migratório e aumentar as reservas que podem ser essenciais para o sucesso reprodutivo quando essas aves chegam até as áreas de procriação (Davison \& Evans, 1988).

O termo "ponto de parada" durante as rotas migratória de aves de praia é ainda muito discutido por vários autores. Melvim \& Temple (1982) estudaram a migração do ganso canadense (Grus canadensis), definindo dois tipos de ponto de parada baseado na fidelidade da 
área e fatores temporais. Segundo estes autores pontos de parada "tradicionais" são as áreas utilizadas durante sucessivos anos e ocupadas durante longos períodos. Os pontos de parada "não tradicionais" são áreas escolhidas oportunisticamente no final do vôo de cada dia, utilizadas durante todo o ano, mas apenas durante um curto período. Entretanto Myers et al. (1990) define vários tipos de ponto de parada, baseado no número de aves de praia que ocorrem anualmente na área. Hands (1988) define área de forrageio onde estas aves passam um período do ano, durante o qual acumulam gordura. Enquanto áreas de descanso são aquelas onde as aves acumulam pouca gordura, passando longos períodos inativas. Entretanto estas definições são arbitrárias pois existe uma interação entre estas duas atividades.

A praia da Ilha Comprida na qual Charadrius semipalmatus se alimenta e descansa é também utilizada por turistas como via de acesso de carros, que transitam livremente pela ilha. Essa presença humana gera visíveis distúrbios, principalmente para as aves que estão descansando durante a maré alta, obrigando-as a voarem de um lugar para outro sucessiva vezes. Esta movimentação faz com que ocorra uma perda desnecessária de energia, como o já registrado por Burger (1991) para outras aves de praia. Essa perda pode ser vital para aves que migram grandes distâncias (Dunn et al., 1988), pois gastam energia que será necessária para sua migração, podendo assim contribuir indiretamente com a mortalidade. Entretanto, Charadrius semipalmatus mostrou uma certa tolerância à presença humana. Locais que houveram uma densidade maior de pessoas na praia, também mostraram densidades maiores destas aves. Tal fato pode ser explicado pela possível disponibilidade de presas e pela ausência de outras espécies de aves que não toleram a presença humana, diminuindo assim a competição pelo alimento.

É importante salientar que a batuíra-debando foi também observada forrageando nas planícies inter-mareais nos manguezais do Complexo Estuarino-Lagunar de CananéiaIguape, durante todo o ano. Sick (1997), relata a ocorrência desta espécie, também em praias lodosas. Esse deslocamento entre paisagens diferentes (praia arenosa e manguezal) pode ser explicado pelo contínuo movimento a procura de alimento por essas aves. As trocas entre diferentes áreas alagadas dentro da pai-

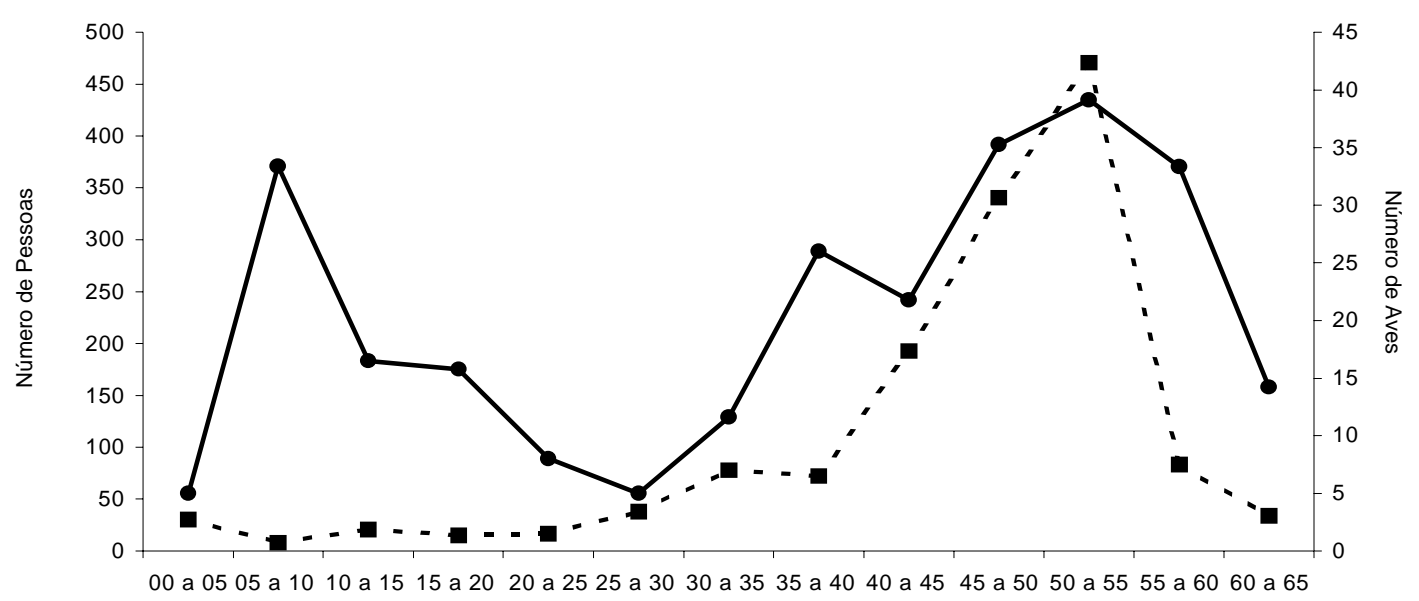

- - Pessoas $\longrightarrow$ Charadrius semipalmatus

Figura 4 - Distribuição de C. semipalmatus e de pessoas ao longo da praia de llha Comprida. 
sagem têm a mesma função ecológica dos movimentos mais restritos entre as manchas que concentram alimento numa mesma área. Estes deslocamentos podem ser explicados, pela variação em termos de escala e tempo da densidade de invertebrados (Rosillon, 1989), sendo que o forrageio por coespecificidade pode rapidamente diminuir a quantidade de invertebrados locais (Helmers, 1991). Quando a abundância de presas locais diminui, as aves de praia movem-se para áreas onde a densidade de alimento é mais alta, (Pyke, 1983). Como a distância entre as áreas alagadas na Ilha Comprida é pequena, o número de áreas com alta densidade de alimento que pode ser explorado individualmente por uma ave aumenta.

Aves de praia e outras espécies migratórias que dependem de áreas alagadas como ponto de parada, estão sendo obrigadas a mudar para outras regiões, devido a rápida mudança na paisagem (Famer \& Parent, 1997). $\mathrm{Na}$ Ilha Comprida este processo se inicia a partir de meados da década de oitenta, através da rápida urbanização. Extensas áreas planas, propícias à especulação imobiliária, cobertas por restinga, foram em primeiro momento preteridas em função da invasão de dunas, devido ao desejo das pessoas em chegar cada vez mais próximo à praia. No município a ação humana tem alterado o ambiente insular, principalmente devido à especulação imobiliária associada ao turismo e ao lazer. Isto pode vir a trazer problemas à avifauna migrante, que faz da llha um importante ponto de parada para sua rota migratória.

\section{AGRADECIMENTOS}

A prefeitura municipal de llha Comprida, pelo apoio durante a realização deste trabalho. Aos funcionários Antônio Carlos de Almeida, Eduardo Antônio Hoff e Onésio Veríssimo do Instituto de Pesca da Secretaria da Agricultura e Abastecimento, Núcleo de Pesquisa do Litoral Sul, que nos ajudaram em diversas etapas do trabalho. Dedicamos esse trabalho a memória do oceanógrafo Luciano Brusque.

\section{BIBLIOGRAFIA}

Barbieri, E.; Mendonça, T.J.; Xavier, S.C.; Bella, S.D. \& T.N. Vetillo. 1999. Composição da ornitofauna da praia de Ilha Comprida, Litoral Sul de São Paulo. In: Cadernos de Resumos expandidos da XII Semana Nacional de Oceanografia. Universidade Estadual do Rio de Janeiro. Rio de Janeiro, RJ. Brasil. 62-64.

Barbieri, E.; Mendonça, T.J. \& S.C. Xavier. 2000. Importância da Ilha Comprida (Litoral sul do Estado de São Paulo) para a migração do maçarico-branco (Calidris alba). Anais do Simpósio Brasileiro sobre Praias Arenosas .Itajaí. Santa Catarina. 258-259.

Belton, W. 1984. Birds of Rio Grande do Sul, Brasil. Part I. Rheidae through Furmariidae. Bull. Amer. Mus. Nat. Hist., 178: 389-636. Bibby, J.C., Burgues, N.D. \& D.A. Hill. 1992. Bird Census Techniques. Academic Press. London. England. 127p.

Burger, J. 1986. The effect of human activity on shorebirds in two Costal Bays in Northeastern United States. Environmental Conservation, 13: 123-127.

Burger, J. \& M. Gochfeld. 1991. Humam activity influence and diurnal and nocturnal foraging of sanderlings (Calidris alba). The Condor 93: 259-265.

Cramp, S. \& K.. Simmons. 1983. Handbook of the birds of Europe, the Middle East, and North Africa, vol. 3. Waders to Gulls. Oxford, Oxford Univ. Press. 230p.

Dunn, P.O.; May, T.A.; Mccollough, M.A. \& M.A. Howe. 1988. Lengh of stay and fat content of migrant semipalmated sanderpipers in eastern Marine. Condor, 90, 824-835. Farmer, A. H. \& Parent, A. H. 1997. Effects of the landscape on shorebird movements at spring migration stopovers. The Condor. 99: 698-707.

Davison, N. \& P. Evens. 1988. Prebreeding acumulation of fat and muscle protein by Artic nesting shorebirds. Proc. Int. Ornithol. Congr. 19: 342-352. 
De La Peña, M. 1986. Guia de aves Argentina. Galliformes a Charadriiformes. Faculdad de Agronomia y Veterenaria, Esperanza, Santa Fé. Argentina. 82p.

Dunn, P.O.; May, T.A.; Mccollough, M.A. \& M.A. Howe. 1988. Lengh of stay and fat content of migrant semipalmated sanderpipers in eastern Marine. Condor, 90, 824-835.

Hands, H.M. 1988. Ecology of migrant shorebirds in northeastern missiouri. M.Sc. Thesis, Univ. Missouri. Columbia. MO.130p.

Helmers, D. 1991. Habitat use by migrant shorebirds and invertebrate availability in a managed wetland complex. M. Sc. Thesis. Univ. Missouri, Columbia, MO.124p.

Manning, T.H. \& A. Macpherson. 1961. A biological investigation of Prince of Wales Island, N. W. T. Trans. R. Can. Inst. 23: 116-239.

Melvin, S.M. \& S.A. Temple. 1982. Migration ecology of Sandhill Cranes: a review. In: J. C. Lewis (ed.) Proceedings of the 1981. Crane Workshop. Natl. Audubon Soc. Tavernier. FL. 73-87.

Mishima, M.; Yamanaka, N.; Pereira, O.M.; Soares, F. Das C.; Sinque, C.; Akaboshi, S. \& O. Jacobsen. 1985. Hidrografia do complexo estuarino-lagunar de Cananéia $\left(25^{\circ} \mathrm{S}, 48^{\circ} \mathrm{W}\right)$, São Paulo, Brasil I. B. Inst. Pesca, São Paulo, 12(3) : 109-121.

Myers, J.P.; Sallaberry, M.A.; Ortiz, E.; Castro, G.; Gordon, L.M.; Maron, J.L.; Schick, C.T.; Tabilo, E.; Antas, P. \& T. Below. 1990. Migration routes of new world sanderlings (Calidris alba). The Auk 107: 172-180.

Myers, J.P.; Connors, P.G. \& F. A. Pitelka. 1979. Territory size in wintering Sanderlings: the effects of prey abudance and intruder density. Auk, 96: 551-561.
Morrison, R.I.G. 1984. Migration systems of some New World shorebirds. Behav. Mer. Org. 6: 123-202.

Pyke, G.H. 1983. Animal movements: an optimal foraging approch., In: I. R. Swingland and P. J. Greenwood (eds). The ecology of animal moviment. Claredon Press. Oxford. 7-31.

Rosillon, D. 1989. The influence of abiotic factors and density dependent mechanisms on between year variation in a strem invertebrate community. Hydrobiology 179 : 25-38.

Sick, H. 1997. Ornitologia brasileira. Rio de Janeiro. Editora Nova Fronteira. 868p.

Silva, J.F. \& R. Herz. 1987. Estudo de microclimas em ambientes de manguezais na região do complexo estuarino-lagunar de Cananéia. In: Simpósio sobre ecossistemas da costa sul e sudeste brasileira: síntese dos conhecimentos, Cananéia, São Paulo, Academia de Ciências do Estado de São Paulo, V.2: 127131.

Suguio, K. \& L. Martins. 1987. Classificação de costas e evolução geológica das planícies litorâneas quartenárias do sudeste e sul do Brasil. Simpósio sobre Ecossistema da Costa Sul e Sudeste Brasileira, Síntese dos conhecimentos. Academy of Sciences. State of S. Paulo. ACIESP. 54I: 1-28.

Tessler, M.G. 1988. Dinâmica sedimentar quartenária no litoral sul paulista. São Paulo. Tese (Doutorado), Instituto de Geologia da Universidade de São Paulo. 276p.

Vooren, C.M. \& A. Chiaradia. 1990. Seasonal Abundance and behaviuor of Coastal Birds on Cassino Beach, Brazil. Ornitologia neotropical. 1: 9-14. 